\section{(6) OPEN ACCESS}

${ }^{1}$ Global Health Institute, Emory University, Atlanta, Georgia, USA

${ }^{2}$ Institute of Public Health, Georgia State University, Atlanta, Georgia, USA

${ }^{3}$ China Medical Board, Cambridge, Massachusetts, USA

${ }^{4}$ Department of Epidemiology and Statistics, Institute of Basic Medical Science, Chinese Academy of Medical Science, Beijing, People's Republic of China

\section{Correspondence to}

Dr Jeffrey P Koplan, Emory University, Global Health Institute, 1599 Clifton Road, Atlanta, GA 30322, USA; jkoplan@emory.edu

Published Online First 22 May 2013

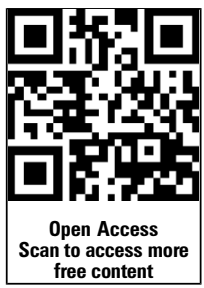

To cite: Koplan JP, Eriksen $\mathrm{M}$, Chen $\mathrm{L}$, et al. Tob Control 2013;22:ii1-ii3.

\title{
The value of research as a component of successful tobacco control in China
}

\author{
Jeffrey P Koplan, ${ }^{1}$ Michael Eriksen, ${ }^{2}$ Lincoln Chen, ${ }^{3}$ Gonghuan Yang ${ }^{4}$
}

\begin{abstract}
Research has been shown to be a critical component of successful national tobacco control programmes. China currently has a small number of dedicated researchers addressing tobacco use and control. We encourage the growth of tobacco research as an academic and governmental field of inquiry. Such research would include multiple foci: biologic and toxicologic, epidemiologic, economic, health promotion, evaluation, policy and regulatory, and legal. Developing a community of tobacco researchers would elevate the tobacco issue on the public policy agenda, encourage transparency among key stakeholders and better identify strategies of tobacco control that could be effective in the Chinese context.
\end{abstract}

The past several decades have seen considerable progress in the reduction of smoking prevalence with changing social norms related to tobacco in many parts of the world, such as Western Europe, Australia, New Zealand, North America and Hong Kong. Many factors have contributed to public health achievement-for example, data collection on tobacco use, community interventions, health education, mass media, surveillance, policy and regulatory change, increased taxation and applied tobacco-control research. ${ }^{12}$ The contributions and importance of tobacco-control research to the global tobacco-control efforts have been documented in several recent reviews. ${ }^{3-5}$

China, arguably the current epicentre of the global tobacco epidemic, is in the early stages of seriously grappling with tobacco control. There are more than 350 million smokers in China, ${ }^{6}$ and more than $50 \%$ of males over the age of 15 smoke, while less than $3 \%$ of adult females smoke. ${ }^{7}$ China grows more tobacco than any other country in the world, ${ }^{8}$ and its tobacco company is government owned. While China has begun to implement many proven tobacco-control elements, such as data collection, community interventions and surveillance, the research component is limited to a handful of talented and dedicated investigators, often encouraged by or partnered with international organisations. Currently, there is little funding from Chinese sources for tobacco-control research in China and little stature or academic credit for working on this topic.

As part of an effort to support tobacco control in China (through a grant from the Bill \& Melinda Gates Foundation), the Emory Global Health Institute and the Think Tank Research Center for Health Development (a Chinese NGO) have sought to promote the development of Chinese academic interest in tobacco-control research. The China
Medical Board and Bloomberg Philanthropies have also supported academic research on tobacco control. In so doing, the primary goal is to establish tobacco-control research as a legitimate and respected field of inquiry in Chinese universities, especially in schools of medicine and public health. As part of this effort, the China Medical Board, the Emory Global Health Institute and the Think Tank organised a major scientific conference on tobacco research in Lijiang city of Yunan Province in Western China in September 2011. The authors and papers in this issue represent the scholarly work of participants joining in that conference.

The experience of many countries is that research is crucial in highlighting academic and policy attention on tobacco control and directing and improving tobacco-control efforts. Countries, including China, can learn from each other's research findings but also must identify aspects of their own culture and circumstances that require modifications in more universally applied approaches. The role of tobacco research in China would appear to be especially important because of China's fewer non-governmental organisations and the important conflicting roles of government in tobacco production, marketing and health protection. A vibrant community of tobacco researchers would keep the issue of tobacco high on the policy agenda, compel transparency among key stakeholders and identify strategies that could be uniquely effective in the Chinese context.

There are several types of research that have proven valuable in tobacco-control efforts: biologic and toxicologic, epidemiologic, economic, health promotion, evaluation, policy and regulatory and legal. Each of them have contributed in unique ways to document the health problem posed by tobacco use, describing in detail the physiologic mechanisms involved and the chemical hazards, identifying the extent of the problem and the nature of the risks, measuring the societal impact and permitting conclusions to be made on the effectiveness of tobacco-control efforts.

\section{BIOLOGIC AND TOXICOLOGIC RESEARCH}

Using animal models in strict research designs, the carcinogenicity of tobacco smoke was demonstrated through biologic research. ${ }^{9}$ Toxicologic research has proven that there is a myriad of hazardous substances inhaled when tobacco is burned and that these substances negatively impact both the smoker ${ }^{10}$ and those exposed to secondhand smoke. ${ }^{11}$

\section{EPIDEMIOLOGIC RESEARCH}

The pioneering work of Doll and Hill in the UK and Wynder and Graham in the USA using large 
data sets demonstrated the health risks of smoking. ${ }^{12}$ The epidemiologic data on tobacco use have permitted countries to regularly assess their tobacco problem on a population and subgroup basis and then monitor improvements or setbacks. It has also documented the extraordinary multiple diseases caused by smoking and the degree of risk that can be attributed to smoking for each disease. This research method will be especially useful in China for the subpopulations of women and youth. Chinese women smoke at rates much lower than men. Chinese adolescents (ages 13-15) have very low smoking rates, but these rates increase dramatically during young adulthood. Tobacco control in China must continue to monitor smoking prevalence and endeavour to keep female smoking rates low while also reducing the number of young adult males who begin to smoke.

\section{ECONOMIC RESEARCH}

In China, tobacco is a significant source of revenue to the government, especially in tobacco growing provinces. Tobacco sales and prices also influence consumption. The understanding of the impact of increasing the purchase price, usually through taxation, to a subsequent decline in cigarette use, has been influential in promoting tax increases in countries across the globe, and with it decreases in smoking have consistently resulted. Analyses of the economics of the tobacco industry and the impact on the farmer have repeatedly shown the minimal profit in growing tobacco for farmers and the relative improvement in their income from alternative crops and alternative livelihoods. ${ }^{13}$ Farming economies and alternatives are important in China as the country produces more than $40 \%$ of the world's tobacco. ${ }^{14}$ Tobacco economics research must also consider the dramatic cigarette pricing in China where there is a 20 -fold difference in the cost of various brands. Finally, any economics research discussion about China must consider the unique position where the tobacco company is government owned, thus the topics of economics and tobacco are more intertwined and complex than in most countries.

\section{HEALTH PROMOTION RESEARCH}

Studies of what interventions are most effective in increasing knowledge about tobacco, attitudes towards smoking and diminishing smoking behaviour permit better investment in the more effective tobacco-control programmes. Intervention approaches also need to be evaluated for urban/rural, age group, socioeconomic level, minority group and other characteristics. Smoking is still the norm in China, and health promotion research must determine how to denormalize smoking in this country.

\section{EVALUATION RESEARCH}

All interventions and initiatives need to be evaluated to determine their overall efficacy, to measure programme outcomes and to document implementation, cost effectiveness and impact. ${ }^{15}$ For example, evaluation of mass media campaigns, targeted interventions for specific subpopulations, the use of anti-tobacco pamphlets and posters and workplace and community programmes need to be studied for effectiveness. As with any country, evaluation research is key to ensure that the appropriate tobacco-control interventions are implemented in China and that they are in fact making the intended impact.

\section{POLICY AND REGULATORY RESEARCH}

It is important to measure the impact of policy and regulatory change, especially when new policies and regulations may not be accompanied by monitoring and enforcement. In China, policy action against tobacco has been initiated but not necessarily enforced, and this is an area of further concern for tobaccocontrol research in China.

\section{LEGAL RESEARCH}

Public and political opinion has been swayed considerably by legal research that has demonstrated the duplicity and manipulative behaviour of the tobacco industry. Such knowledge has encouraged stronger governmental policy and regulatory action and has the potential to do the same in China, although possibly complicated by the reality of tobacco industry government ownership.

\section{CONCLUSIONS}

Much of the results of the above types of research accomplished globally are easily applicable to the Chinese landscape. The biologic outcomes of smoking are likely to be similar. Secondhand smoke will pose the same health hazards. Enacting and enforcing smoke-free places will diminish exposure to smoking hazards. Higher purchase prices are likely to diminish smoking rates, etc.

But it also may be useful for research to investigate whether the patterns of diseases, their severity or the effectiveness of various tobacco-control interventions differ in the Chinese context, as opposed to other populations. Biologic, toxicologic and epidemiologic differences are unlikely, but documenting such information for China will help combat the myth that 'Chinese are different' and that they may be more resistant to the hazards of smoking. However, it is possible that research on the components of Chinese tobacco smoke may reveal more toxic levels than in Western products. Local documentation of healthcare costs attributed to tobacco use may help influence local officials to enact more stringent regulations. The relationship between costs and smoking may be more complex in China due to wider pricing range of various brands and the government-owned tobacco company. The public health impact of tax increases, which is relatively straightforward in most countries, may be modulated by smokers down-shifting to cheaper brands, or by the tobacco monopoly manipulating retail price so as to negate the impact of increased tax, as was recently done in China. ${ }^{8}$ Policy research will require rigorous investigation of enforcement and subsequent impact. Legal research will be a challenge in a relatively new and changing legal system with a government-owned tobacco industry and considerable limits on industry disclosure and without freedom of information regulations. The belief in the value of 'top-down' tobacco control and the particular influence of the personal habits of political leaders needs study and validation.

Effective and efficient tobacco control in China will require a rigorous and energetic research component. Particular attention to study design, epidemiological and biostatistical methods and careful attention to data accuracy, quality, collection and analysis will be necessary for tobacco-control studies to be of high quality and suitable for publication and application. China Centers for Disease Control and Prevention (CDC) currently conducts tobacco research, largely concentrating on epidemiologic and surveillance data. All of the necessary types of research need to be enhanced and expanded. Universities, their health science centres and their economic, legal, agricultural and public policy departments in particular are the logical sites for such research. For tobacco-control research to flourish in China, there will need to be financial support and enhanced academic stature for the courageous investigators who choose this for their field of inquiry.

Contributors All the authors participated in the conceptualisation and writing of this paper. 
Competing interests None.

Provenance and peer review Not commissioned; externally peer reviewed.

Open Access This is an Open Access article distributed in accordance with the Creative Commons Attribution Non Commercial (CC BY-NC 3.0) license, which permits others to distribute, remix, adapt, build upon this work non-commercially, and license their derivative works on different terms, provided the original work is properly cited and the use is non-commercial. See: http://creativecommons.org/licenses/by-nc/3.0/

\section{REFERENCES}

1 World Health Organization. MPOWER programme, 2013. http://www.who.int/ tobacco/mpower/en/ (accessed 26 Feb 2013).

2 Centers for Disease Control and Prevention. Best practices for comprehensive tobacco control programs-2007. Atlanta: U.S. Department of Health and Human Services, Centers for Disease Control and Prevention, National Center for Chronic Disease Prevention and Health Promotion, Office on Smoking and Health; October 2007. Reprinted with corrections. http://www.cdc.gov/tobacco/stateandcommunity/ best_practices/index.htm (accessed 26 Feb 2013).

3 Warner K, Tam J. The impact of tobacco control research on policy: 20 years of progress. Tob Control 2012;21:103-9.

4 Lando HA, Borrelli B, Klein LC, et al. The landscape in global tobacco control research: a guide to gaining and foothold. Am J Publ Health 2005;95:939-45.

5 McDonald PW, Viehbeck S, Robinson SJ, et al. Building research capacity for evidence-informed tobacco control in Canada: a case description. Tob Induced Dis 2009;5.

6 Netscribes. Tobacco Market in China, 2012.

7 World Health Organization. Report on the Global Tobacco Epidemic, 2011: warning about the dangers of tobacco. Geneva: World Health Organization. http://www. who.int/tobacco/global_report/2011/en/ (accessed 26 Feb 2013).

8 Food and Agricultural Organization. FAOSTAT data, tobacco unmanufactured: area harvested, 2009. http://faostat.fao.org/site/567/DesktopDefault.aspx? Pagel $D=567$ \#ancor (accessed 26 Feb 2013).
9 U.S. Department of Health and Human Services. How tobacco smoke causes disease: the biology and behavioral basis for smoking-attributable disease: a report of the Surgeon General. Atlanta, GA: U.S. Department of Health and Human Services, Centers for Disease Control and Prevention, National Center for Chronic Disease Prevention and Health Promotion, Office on Smoking and Health, 2010. http://www.surgeongeneral.gov/library/reports/tobaccosmoke/full_report.pdf (accessed 26 Feb 2013).

10 U.S. Department of Health and Human Services. The health consequences of smoking — cancer, a report of the Surgeon General. Atlanta, GA: U.S. Department of Health and Human Services, Centers for Disease Control and Prevention, National Center for Chronic Disease Prevention and Health Promotion, Office on Smoking and Health, 1982. http://profiles.nIm.nih.gov/ps/access/NNBCDW.pdf (accessed 26 Feb 2013).

11 U.S. Department of Health and Human Services. The health consequences of involuntary exposure to tobacco smoke: a report of the Surgeon General. Atlanta, GA: U.S. Department of Health and Human Services, Centers for Disease Control and Prevention, Coordinating Center for Health Promotion, National Center for Chronic Disease Prevention and Health Promotion, Office on Smoking and Health, 2006. http://www.surgeongeneral.gov/library/reports/secondhandsmoke/index.html (accessed 26 Feb 2013).

12 Proctor RN. Golden holocaust: origins of the cigarette catastrophe and the case for abolition. University of California Press, 2011.

13 Eriksen M, Mackay J, Ross H. The tobacco atlas. 4th edn. Atlanta, GA: American Cancer Society; New York, NY: World Lung Foundation; 2012. http://www. TobaccoAtlas.org.

14 Food and Agricultural Organization. FAOSTAT data, tobacco unmanufactured: area harvested, 2009. http://faostat.fao.org/site/567/DesktopDefault.aspx? PagelD=567\#ancor (accessed 26 Feb 2013).

15 MacDonald G, Starr G, Schooley M, et al. Introduction to Program Evaluation for Comprehensive Tobacco Control Programs. Atlanta (GA): Centers for Disease Control and Prevention, 2001. http://www.cdc.gov/tobacco/tobacco_control_programs/ surveillance_evaluation/evaluation_manual/index.htm (accessed 26 Feb 2013). 